\title{
ТЕХНИКО-ЭКОНОМИЧЕСКАЯ ЦЕЛЕСООБРАЗНОСТЬ ПРИМЕНЕНИЯ ГАБИОНОВ
}

\author{
(C) 2021 Преснов Олег Михайлович \\ кандидат технических наук, доцент \\ Сибирский федеральный университет, Россия, Красноярск \\ E-mail: OPresnov@sfu-kras.ru \\ (c) 2021 Быкова Алёна Сергеевна \\ студент экспертизы и управления недвижимостью \\ Сибирский федеральный университет, Россия, Красноярск \\ E-mail: alena.bykova.2000@bk.ru \\ (c) 2021 Мутовина Анна Сергеевна \\ студент экспертизы и управления недвижимостью \\ Сибирский федеральный университет, Россия, Красноярск \\ E-mail:mutovina999@gmail.com \\ (c) 2021 Паданаева Кристина Сергеевна \\ студент экспертизы и управления недвижимостью \\ Сибирский федеральный университет, Россия, Красноярск \\ E-mail: k.padanaeva@mail.ru \\ (c) 2021 Примиренко Алина Александровна \\ студент экспертизы и управления недвижимостью \\ Сибирский федеральный университет, Россия, Красноярск \\ E-mail: al.ina@mail.ru
}

На сегодняшний день строительство близ водных объектов актуально. В связи с этим развиваются технологии берегоукрепления, чтобы обеспечить безопасную эксплуатацию зданий, сооружений близ водных объектов. Габионы - конструкции из металлического сетчатого каркаса, заполненного различными материалами. Укрепление берегов водоемов, склонов насыпей и холмов с помощью габионов технически и экономически более целесообразно, чем с помощью традиционных способов.

Ключевые слова: габионы, экономичность, водная эрозия, ландшафт, долговечность, экологичность, грунт, водопроницаемость.

При строительстве ландшафт не всегда отличается ровной поверхностью. Для того чтобы укрепить грунт, стабилизировать покрытие, используются габионы. Они отлично справляются с армированием почвы. Их применяют для защиты трубопровода, сооружений, которые возведены на грунте. Такая металлоконструкция способна защитить здание от негативного природного воздействия. Также, если строительство происходит на склоне, применяются эти конструкции для обеспечения стабильной поверхности.

Существует множество современных проектов, которые используют габионные стены в различных конструкциях и проектных решени- ях, включая фасады зданий и ограждения собственности. Декоративные габионные элементы используют во внутренней и наружней отделке, дизайне сада и ландшафтном дизайне. Габионные элементы обеспечивают подходящую среду для роста корней растений.

Габионные стены могут быть выполнены в прямоугольной, квадратной и цилиндрической формах. Определить правильный тип габиона важно с экономической точки зрения и функциональности конструкции. Более активно используют сетчатую проволочную конструкцию, которая выпускается обычно в коробчатой форме различных размеров. Пример конструктивной схемы габионов представлен на рисунке 1 [1]. 


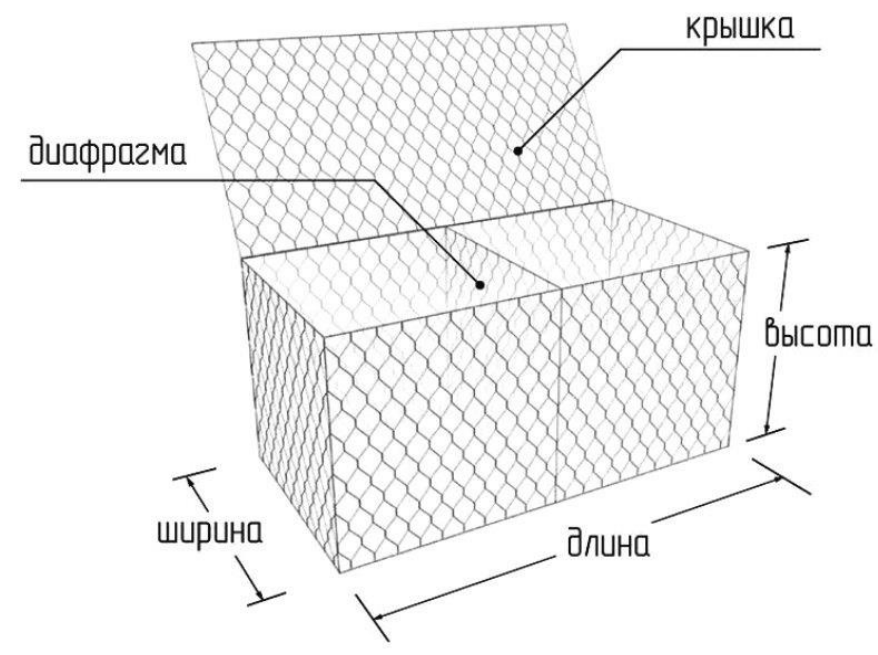

Рисунок 1. Конструктивная схема коробчатых габионов с обозначением основных параметров

Габионы также используются в качестве временных противопаводковых стен и для изменения направления силы паводковой воды. Ступенчатые габионы улучшают рассеивание энергии в каналах.

Подпорные конструкции габионного типа являются одним из наиболее экономичных и эффективных решений для стабилизации естественного уклона грунта. Габионные стены также предпочтительны для эффективности дренажа вместо гравитационных стен. Настоящая статья представляет собой краткое изложение определения, типов, областей применения и преимуществ габионных элементов.

Проектирование подпорных стен, направленное на поддержание уровня грунта на двух разных уровнях, является одной из основных тем исследований в области геотехники. Га- бионные стены широко используются в мире и уже более века используются в многочисленных проектах борьбы с эрозией, мелиоративных работах почвы, строительстве каналов ручьев и подпорных сооружений. Габионные стены могут быть спроектированы как жесткие, полужесткие и гибкие в зависимости от площади строительства, состояния грунтовых вод, стоимости и цели использования.

В последние годы габионы нашли широкое применение при строительстве и укреплении крутых склонов в России. Габионы применялись при строительстве водозаборного сооружения Унэгэтэйской оросительной системы в Бурятии. Изготовлением сетки и технологии по использованию габионов занималась БОМС СибНИИГиМ. На рисунках 2 и 3 приведены примеры габионных конструкций в г. Красноярске.

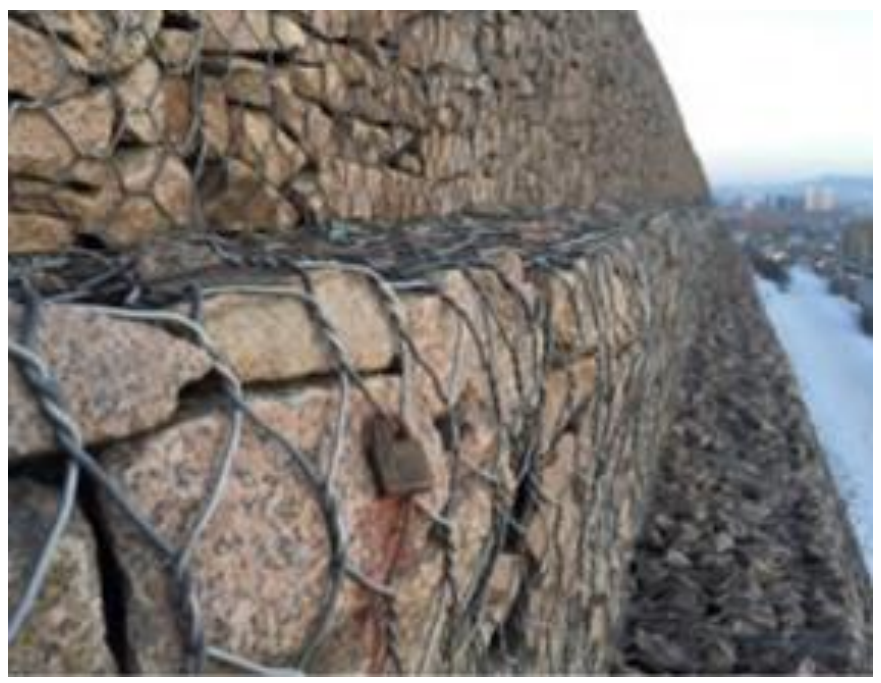

Рисунок 2. Габионы у ТЦ «Июнь» г. Красноярск 


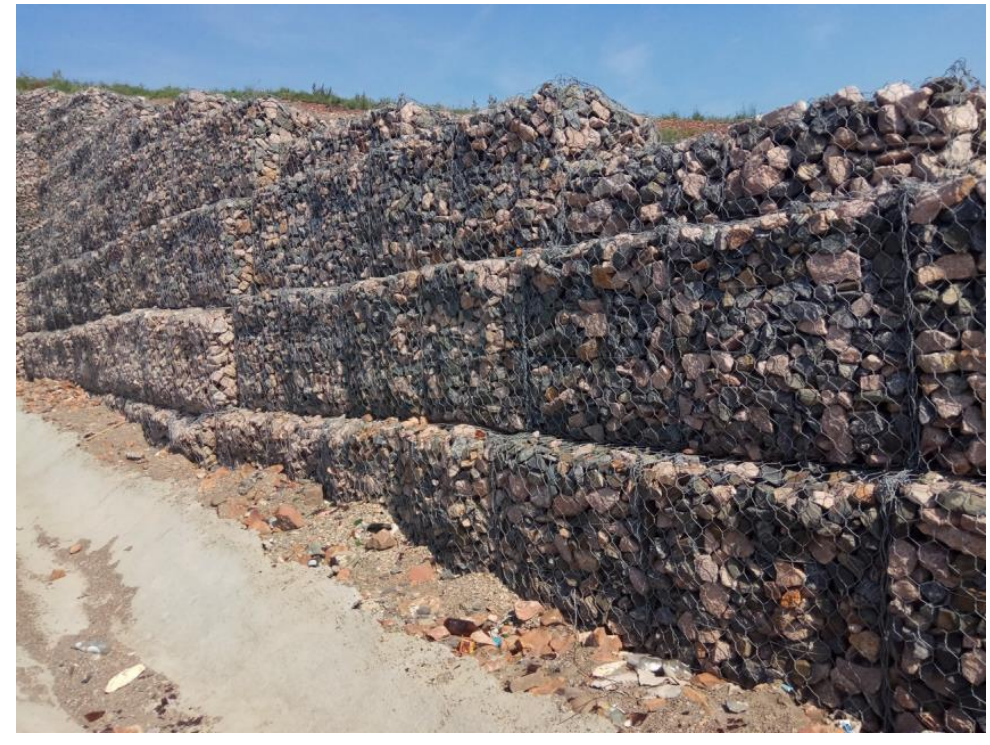

Рисунок 3. Габионные конструкции на серпантине на горе Сопка г. Красноярск

Габионы сохранили свою полезность на протяжении многих лет благодаря нескольким отличительным характеристикам, которые их определяют. Например, они отлично стабилизируют берега и склоны и направляют поток воды вокруг зданий, а также ценятся за их модульность. Кроме того, многие современные здания используют габионные стены в своем строительстве для внешнего вида.

Были проанализированы возможности рассматриваемых конструкций, результатом которого было выявлено, что габионы являются более рациональными и экономичными, в отличии от традиционных конструкций. Это вызвано рядом характеристик и особенностей, которые определяют габионные конструкции в целом. Самые распространенные особенности данных конструкций [3]:

- гибкость. Габионные элементы представляют собой удобное решение для грунтов с высоким потенциалом оседания и набухания. Гибкие габионные элементы не трескаются и не подвержены воздействию землетрясений, так как гравитационные подпорные стенки.

- проницаемость. Габионные элементы не требуют дополнительной дренажной системы из-за зазоров между заполняющими материалами.

- сопротивляемость большим нагрузкам;

- прочность лицевых граней и каркасноармирующих элементов;

- значительная устойчивость к коррозионным влияниям от атмосферных осадков и воды;
- допустимость использования с традиционными разновидностями укреплений дорожно-мостовых строений, повышая результативность и экологичность использования комбинированных конструкций;

- наиболее большая и долговременная дренирующая способность габионов в сравнении с традиционными стройматериалами, установками, блоками и водоотводными устройствами;

- экономичность. Низкая стоимость доставки рассматриваемых конструкций обеспечена легкостью упаковки. Монтирование габионной сетки не требует должной квалифицированной рабочей силы, а значит, и трудозатраты невелики. Пломбировочный материал может быть легко доставлен из карьера, расположенного рядом с рабочей площадкой. Затраты на техническое обслуживание габионных элементов чрезвычайно низки.

- экологичность. Габионные элементы экологически совместимы. Зазоры в почве между заполняющими материалами позволяют плантации расти с течением времени. Габионные элементы не подвержены влиянию природных явлений.

- эстетика. В архитектуре габионные элементы используются для внутреннего и наружного обустройства. Габионы имеют естественный внешний вид.

Габионы могут поставляться в любую точку страны и мира. Данные конструкции из сварной сетки обычно поставляются в плоской упаковке для удобства транспортировки. Габионные 


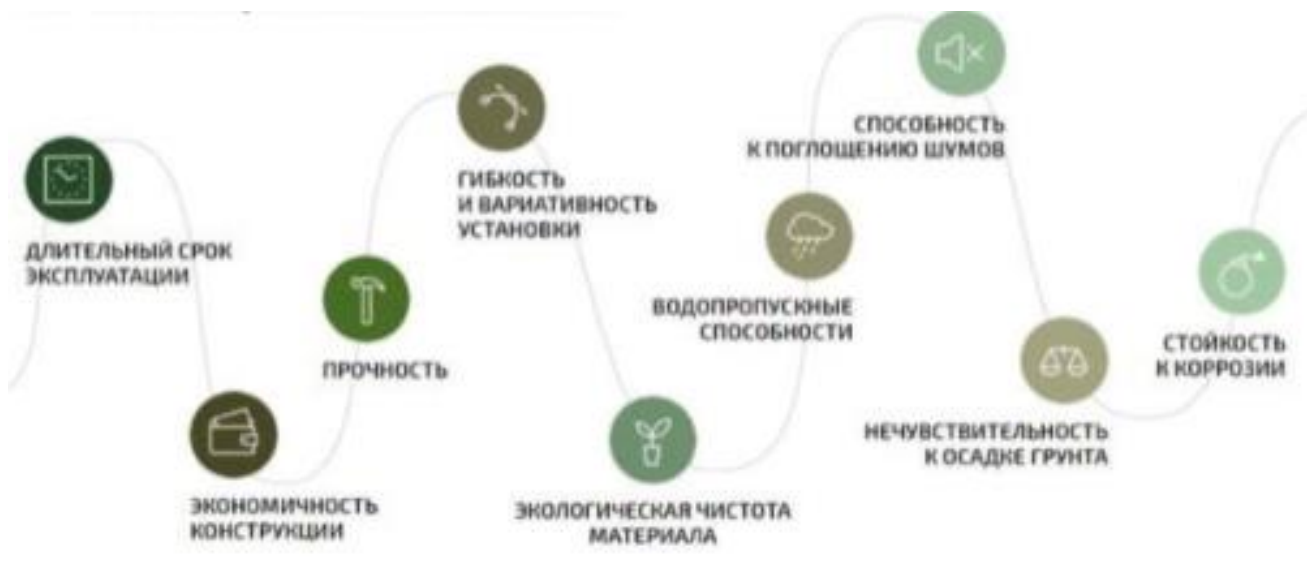

Рисунок 4. Схема достоинств габионных конструкций

конструкции могут быть предварительно заполнены, но только в случае крайней необходимости из-за высоких затрат на транспортировку и монтаж и нарушения способности стены перераспределять нагрузки, потому что соседние габионы не соединены между собой.

Габионы обладают не только весьма широкими возможностями их применения, качеством габионной продукции и централизованностью поставок индустриального производства, но экономической выгодой. Стоимость самих конструкций невелика и составляет примерно 10$12 \%$ от общей стоимости работ «под-ключ».

Основные затраты приходятся на каменьзаполнитель для габионов, и если имеется возможности приобрести недорогой камень поблизости от места производства работ, то общие затраты окупят проект. Дополнительно примерно до 40\% снизит расходы возможность собственными силами выполнить работы по установке габионов. Так, стоимость $1 \mathrm{~m}^{3}$ раствора с доставкой составит около 4500 руб, в то время как $1 \mathrm{~m}^{3}$ камня с доставкой обойдется в 3000 руб плюс $1 \mathrm{~m}^{3}$ сетки габиона до 800 руб. Экономия в пользу габионов может составлять от 10 до 30\%.

Вывод: Использование природных материалов в строительстве за последние десятилетия значительно сократилось. В строительной промышленности и ландшафтном дизайне предпочтение обычно отдается промышленным материалам. Однако человеческий глаз и естественная среда обитания отказываются от промышленных материалов.

Габионные элементы предпочтительны изза их гибкости, проницаемости, низкой стоимости, экологичности и эстетичности в отличии от традиционных конструкций. В современных технологиях производства гибких проводов и использования этих проводов до 30-100 лет без деформации делает габионные элементы незаменимыми.

\section{Библиографический список}

1. ГОСТ Р 52132-2003 Изделия из сетки для габионных конструкций. Технические условия

2. ГеоИнфо ЭКСПО - 2020. Габионы: достоинства, недостатки и возможность новых решений: [Электронных pecypc]: URL: https://www.geoinfo.ru/product/konferencii-geoinfo/geoinfo-ehkspo-2020-41468.shtml (дата обращения: 10.03.2021)

3. Методические рекомендации по применению габионных конструкций в дорожно-мостовом строительстве. Под общ. ред. Б. Ф.Перевоэникоаа / ООО «Организатор». ФГУП «Союздорпроект». М,: 2001-267 с. 